\title{
Analysis of genetic variability of commercial melon cultivars using SSR molecular markers
}

\author{
N. Carvalho ${ }^{1}$, F.M. Canela ${ }^{2}$, P.H.S. Leite ${ }^{2}$, M.A. Ferreira ${ }^{3}$, V.R. Oliveira ${ }^{4}$, \\ M.F. Santos ${ }^{5}$, N.O.S. Souza ${ }^{6}$ and G.S.C. Buso ${ }^{3}$ \\ ${ }^{1}$ Programa de Pós-Graduação em Recursos Genéticos, \\ Universidade de Brasília, Brasília, DF, Brasil \\ ${ }^{2}$ Faculdade de Agronomia e Medicina Veterinária, \\ Universidade de Brasília, Brasília, DF, Brasil \\ ${ }^{3}$ Laboratório de Genética Vegetal, \\ EMBRAPA Recursos Genéticos e Biotecnologia, Brasília, DF, Brasil \\ ${ }^{4}$ EMBRAPA Hortaliças, Brasília, DF, Brasil \\ ${ }^{5}$ EMBRAPA Gado de Corte, Campo Grande, MS, Brasil \\ ${ }^{6}$ Laboratório de Sementes, Universidade de Brasília, Brasília, DF, Brasil \\ Corresponding author: N. Carvalho \\ E-mail: nayaracarvalho87@gmail.com \\ Genet. Mol. Res. 16 (3): gmr16039739 \\ Received May 26, 2017 \\ Accepted August 4, 2017 \\ Published August 31, 2017 \\ DOI http://dx.doi.org/10.4238/gmr16039739
}

Copyright $(C 2017$ The Authors. This is an open-access article distributed under the terms of the Creative Commons Attribution ShareAlike (CC BY-SA) 4.0 License.

ABSTRACT. Taking into account the scenario of melon production (Cucumis melo L.) in Brazil, it is notable the importance of the culture in the fruit market. The preference of the national market is concentrated in the fruits of the yellow type. Therefore, it is possible that the genetic base of the commercial cultivars is relatively narrow due to the loss of important genes in the breeding process, and it is possible to introgress external genes for increasing recombination possibilities that generate sources of resistance to the main diseases and superior genotypes. This study evaluated the genetic variability of 87 melon accessions composed of 72 commercial cultivars belonging to the Inodorus and Cantaloupensis groups and 15 plant introductions (PIs). Forty-four

Genetics and Molecular Research 16 (3): gmr16039739 
polymorphic SSR primers were used to amplify a total of 202 alleles. The expected heterozygosity presented an average of 0.519 and the PIC index of 0.458 , being moderately informative. The dendrogram generated for the 72 cultivars grouped the genotypes into 2 main groups, and there was no association with the classification of groups of the genotypes in the grouping. The number of SSR markers was sufficient to predict wide genetic variability among the cultivars studied, with the similarity between 0.35 and 0.98 . The dendrogram presented for the 72 cultivars and the 15 PI genotypes was not associated with the classification of the genotypes in the grouping, and the 15 PIs were well dispersed with similarity indexes that resemble the two groups studied. A set of 25 primers was identified that were useful in distinguishing the 72 cultivars. These primers can be used in later research with the cultivars, as well as in crop protection situations, being an important tool in the useful and rapid distinction of genotypes, and in commercial disputes regarding the certification of the main melon cultivars used in the country.

Key words: Cucumis melo L.; Genetic variability; Commercial cultivars; Molecular markers; SSR

\section{INTRODUCTION}

Melon (Cucumis melo L.) is a fruit that has a great representation in the global fruit market, and in Brazil a large amount of the fruit is for exportation, especially in the Northeast, which concentrates more than $95.8 \%$ of the national production generating many jobs and contributing to the socioeconomic development of the region. It is an herbaceous plant that belongs to the Cucurbitaceae family and features many disagreements as to its origin, but the most likely regions are southwestern Africa and peninsular region of India (Mallick and Massui, 1986).

The species has a wide phenotypic diversity in its varieties, which does not necessarily indicate a large genetic variability. The most cultivated melons in Brazil belong to the Inodorus yellow-type group, although there is a tendency to increase demand for melons of the Cantaloupensis group, mainly for export. To keep on a melon breeding program, it is required to assess the genetic variation that is important for efficient management. Detection and usage of the genetic variation and cultivar identification are, therefore, some important tasks for melon breeders. Traditionally, morphological descriptors have already been employed by breeders to characterize, register, and release new varieties. However, the limitations of this kind of descriptor have created the necessity to find alternatives.

Molecular markers can be options to characterize germplasm and protect new cultivars without environmental interference. Molecular analyses using techniques of modern biotechnology, especially molecular markers, contribute significantly to these studies, which generate potentially important information for broadening the genetic base of breeding programs (Shiran et al., 2007).

Some authors assume that there is genetic erosion in C. melo L. (Garcia et al., 1998; Queiroz, 2004), and in fact, the improvement of melon in Brazil is based on the yellow-

Genetics and Molecular Research 16 (3): gmr16039739 
type melon, due to its larger consumption, which may have contributed to the loss of important genes present in wild species or varieties planted by small farmers. Thus, studies of characterization and analysis of genetic variability of cultivars permit evaluation of the culture genetic basis, and there may be potential introduction of genes of interest that contribute to higher recombination possibilities generating sources of resistance to major diseases and superior genotypes (heterosis), and significantly contributing to the aid of the melon breeding.

Another promising application of the use of molecular markers is in its use for plant variety protection and resolving trade disputes. For some species, such as watermelon and grapes, there are already studies in this context (Jarret et al., 1997; Guerra-Sanz, 2002; Kwon et al., 2010), but with the $C$. melo L. species, reports were not published yet.

Given the above, this study aimed to evaluate the genetic basis of commercial melon cultivars through the study of genetic variability of genotypes belonging to Inodorus and Cantaloupensis groups, to generate a reference data and support for cultivar protection, and possible commercial dispute arbitration, based on the allelic pattern and genetic distance of the main commercial cultivars using microsatellite markers, and to guide breeding programs and management of genetic resources.

\section{MATERIAL AND METHODS}

\section{Plant material}

The obtained material for the study was from the Germplasm Melon Bank of the Embrapa Vegetables breeding program, and consisted of 72 commercial cultivars, 44 belonging to the Inodorus group, 28 belonging to the Cantaloupensis group, and 15 plant introductions (PI) (Tables S1 and S2), collected in a greenhouse at seedling stage. The study was conducted at the Plant Genetics Laboratory of the Embrapa Genetic Resources and Biotechnology.

\section{Genomic DNA extraction and PCR amplification}

The genomic DNA was extracted using the CTAB 2\% protocol with modifications (Ferreira and Grattapaglia, 1998; Buso 2005), quantified on 1\% agarose gel to verify the quantity and quality, and diluted in Mili-Q water to the concentration of $3 \mathrm{ng} / \mu \mathrm{L}$. The PCRs totalized a volume of $13 \mu \mathrm{L}: 3 \mu \mathrm{L}$ DNA at $3 \mathrm{ng} / \mu \mathrm{L} ; 3 \mu \mathrm{L}$ SSR primer at $0.9 \mu \mathrm{M} ; 7 \mu \mathrm{L}$ of mix containing $2.65 \mu \mathrm{L}$ water; $1.30 \mu \mathrm{L}$ dNTP at $2.5 \mu \mathrm{M} ; 1.30 \mu \mathrm{L}$ BSA at $2.5 \mathrm{mg} / \mathrm{mL} ; 1.30 \mu \mathrm{L} 10 \mathrm{X}$ buffer $(100 \mu \mathrm{M}$ Tris-HCl, $\mathrm{pH} 8.3 ; 500 \mu \mathrm{M} \mathrm{KCl}) ; 0.25 \mu \mathrm{L} 50 \mathrm{mM} \mathrm{MgCl}_{2}$ and $0.20 \mu \mathrm{L}$ Taq DNA polymerase at $5.0 \mathrm{U} / \mu \mathrm{L}$.

The conditions of the amplification reactions were as follows: an initial cycle of $5 \mathrm{~min}$ at $94^{\circ} \mathrm{C}$, followed by 30 cycles of $1 \mathrm{~min}$ at $94^{\circ} \mathrm{C}, 1 \mathrm{~min}$ at the annealing temperature optimized for each primer (Table S3), and $1 \mathrm{~min}$ at $72^{\circ} \mathrm{C}$, followed by one final cycle of $10 \mathrm{~min}$ at $72^{\circ} \mathrm{C}$.

The SSR primers utilized were developed by Ritschel et al. (2004) and Ohse (2005). The primer pairs $\mathrm{F}$ and $\mathrm{R}$ (forward and reverse) were diluted to $0.9 \mu \mathrm{M}$, tested and optimized in a reduced genotype sample and selected according to the occurrence of polymorphisms. The selected primers were used with all genotypes (Table S3).

PCR products were separated under denaturing conditions on 5\% polyacrylamide gels and stained with silver nitrate (Bassam et al., 1991) and the size was estimated by comparison to a 10-bp DNA ladder.

Genetics and Molecular Research 16 (3): gmr16039739 


\section{Statistical analysis of the generated markers}

The SSR markers were codified as $\mathrm{x} / \mathrm{y}$ (size of each allele in its locus), and the genotyping data of the 72 cultivars were analyzed using the CERVUS software version 3.0.3 (Marshall et al., 1998; Kalinowski et al., 2007), that calculated the number of observed genotypes per locus, the number of alleles per locus, observed heterozygosity $\left(H_{\mathrm{O}}\right)$, expected heterozygosity $\left(H_{\mathrm{E}}\right)$, polymorphism information content (PIC), and the probabilities of no exclusion of parental 1 (NE-1P) and 2 (NE-2P). The program simulates the paternity using $[1-(N E-1 P)] \times 100$ for parental 1 and [1 - (NE - 2P)] x 100 for parental 2. The primers with greater NE-1P and NE-2P indexes have the smallest PIC, being less informative. These primers were excluded one by one until obtaining a minimum number of primers that could distinguish each of the 72 cultivars with $99.99 \%$ index of parental exclusion.

The genotyping data of the 72 cultivars and 15 PIs were submitted to the NTSYS software (Rohlf, 1992), which provided the genetic similarity index between each pair of accession. The coefficient used was BAND (band-sharing coefficient of Lynch) (Lynch, 1990). Based on these indexes, a similarity matrix was established that formed the basis for the cluster analysis and dispersion (Faleiro, 2007). Band coefficient is based on the sum of the proportion of common alleles between two genotypes divided by twice the number of alleles tested. The cluster analysis was based on the unweighted pair-group method using the arithmetic average (UPGMA). After this analysis, the software generated a dendrogram with the grouping of the analyzed genotypes.

\section{RESULTS AND DISCUSSION}

Forty-four polymorphic primers were selected to analyze the 72 commercial cultivars. The 44 loci amplified a total of 202 alleles with a mean of 4.59 alleles per locus (Table S4); an allele number superior to that described by Aragão (2010), who analyzed 41 melon accessions using 17 SSR primers, also developed by Ritschel et al. (2004), who amplified 41 alleles. This allele number is superior to that described by Kaçar et al. (2012), who studied the genetic diversity of 81 melon genotypes of Turkey in comparison to 15 reference genotypes obtained in France. These authors amplified 123 alleles from 20 SSR primers with a mean of 6.15 alleles per locus; this medium is superior to the one found in this study. This greater discrepancy between the numbers of alleles per locus may indicate a greater genetic variability of their material.

The number of alleles is greater when different botanical groups are analyzed. Staub et al. (2000) compared melon accessions of different botanical groups (Cantaloupensis, Inodorus, Conomon, and Flexuosus) using seven SSR polymorphic markers that amplified a total of 54 alleles. Besides, 93 alleles were detected in a study that evaluated the divergence of 40 melon accessions belonging to Cantaloupensis, Inodorus, and Conomon groups by 25 SSR markers (Ritschel et al., 2004). The number of alleles described herein was inferior to that found by Tzuri et al. (2006), who evaluated 102 genotypes of various types of melon (Cantaloupe, Charentais, Honey Dew, Ananas, Galia, Inodorus, and Oriental melon) by PCR and electrophoresis on polyacrylamide gel, and amplified a total of 212 alleles using 48 SSR polymorphic primers.

According to Botstein et al. (1980), the PIC is also indicative of the marker quality in genetic studies. PIC with values greater than 0.5 is considered very informative, with values

Genetics and Molecular Research 16 (3): gmr16039739 
between 0.25 and 0.50 , medium informative, and with values lower than 0.25 , less informative. The PIC varied from 0.201 in locus CM305 to 0.799 in locus CM89, the latter being the most informative locus (Table S4). The mean PIC value of 0.458 was averagely informative for the loci in question. Henane et al. (2015) demonstrated with 20 SSR markers, a wide diversity among varieties of melon (C. melo L. and C. melo var. Flexuosus) in Tunisia, evidenced by the PIC ranging from 0.43 to 0.92 , with mean of 0.454 and the number of alleles per locus ranged from two to three, averaging 2.54, concluding that these varieties are an important source of diversity.

The $H_{\mathrm{E}}$ varied from 0.228 in locus CM305 to 0.828 in locus CM89 with an average of 0.519 (Table S4). The $H_{\mathrm{O}}$ ranged from 0.056 in locus CM244, being the locus with the highest proportion of homozygotes, to 0.451 in locus CM08 with the least homozygous genotypes (Table S4).

The primers with higher levels of NE-1P, NE-2P and lower rates of PIC (CMBR83, CM116, CM128, CM161, CM185, CM224, CM230, CM244, CM303, CM305, CM311, CM319, CM320,CM321, CM331, CM335, CM347, CM351, and CM354) were excluded one by one and it was possible to identify a set of 25 primers (CM08, CM14, CM15, CM25, CM33, CM40, CM43, CM51, CMBR64, CM72, CM89, CM104, CM107, CM125, CM139, CM176, CM177, CM197, CM227, CM245, CM248, CM254, CM342, CM336, and CM337) that was useful in distinguishing the 72 cultivars with exclusion parental index of $99.99 \%$. These primers can be used in further research with the cultivars analyzed in this study, as well as in their differentiation, which can be an important tool in the useful and fast distinction of genotypes.

Gama et al. (2013) used 10 SSR primers to characterize 17 watermelon cultivars and amplified a total of 34 alleles with similarity indexes ranging from 0.34 to 1 concluding that the analyzed loci were not sufficient to distinguish these cultivars.

Two dendrograms were generated, one with just the 72 cultivars and other with 72 cultivars and 15 PI. The resulting dendrogram of the SSR analysis for the 72 cultivars (Figure S1) grouped genotypes with a genetic similarity ranging from 0.355 to 0.98 . It was observed clustering of accessions in two groups ( 1 and 2 ) with $35.5 \%$ similarity between them. The first group had most genotypes and was divided into 2 subgroups (1.1 and 1.2) with $46.5 \%$ similarity to each other. The subgroup 1.2 only had genotype 2 (referring to Jangada melon, type yellow). Potiguar (9) and Goldex (13) cultivars, both belonging to the Inodorus group of yellow type, showed the greatest similarity (98\%), being grouped in subgroup 1.1. The second group presented was divided into two subgroups (2.1 and 2.2). It was observed similarity of $43 \%$ between farming Cristobal (75), Cantaloupensis group, Net type, and Gold Pride cultivars (7) and Best Bite (20) both Inodorus, yellow type grouped in subgroup 2.1. The subgroup 2.2 showed only Iracema (17) and Mel 22 (43) cultivars, both Inodorus, yellow type, with 52\% similarity between them.

Thus, it could be observed that there was no association with the classification of genotypes in the group. However, most Inodorus genotypes were grouped in subgroup A and most Cantaloupensis genotypes were grouped in subgroup B, both subgroups of group 1 . The number of SSR markers was enough to predict a wide genetic variability among cultivars since none of them showed genetic similarity equal to 1. Additionally, Garcia et al. (1998) grouped perfectly 32 strains of different melon groups using molecular markers and agronomic traits.

Information on diversity and genetic distance can also assist in expanding the genetic basis for the development of breeding programs (Freitas and Bered, 2003). Accordingly, 15 PIs were analyzed together with 72 cultivars. The resulting dendrogram from the SSR analysis of the 72 cultivars and 15 PI (Figure S2) grouped genotypes with the same genetic similarity of

Genetics and Molecular Research 16 (3): gmr16039739 
the first analysis. The 15 PIs did not alter the grouping, as compared with the analysis without their inclusion. It looks like that their inclusion cannot increase the variability. Besides, some of them were very similar between themselves, as PIs 51, 52, 56, and 60. Again there was no association with the classification of genotypes in the cluster, and the number of SSR markers was sufficient to predict a wide genetic variability among the studied cultivars since none of them presented genetic similarity equal to 1 . The 15 PI genotypes $(45,46,47,48,49,50$, $51,52,53,54,55,56,57,58$, and 60 ) were well dispersed with similarities that resemble the two groups studied (Inodorus and Cantaloupensis). Thus, it would be desirable to introduce divergent introductions according to the groups studied.

\section{CONCLUSION}

We concluded that the 72 genotypes analyzed have a wide genetic base, representing, therefore, a great source of genetic variability for the germplasm of commercial cultivars. The cultivars Jangada (2) of the yellow type (Inodorus group) and Cristobal (75) of the Net type (Cantaloupensis group) stood out being grouped individually, which can be justified by the unique combination of alleles since no allele exclusive of these genotypes were observed.

It was possible to identify a set of 25 primers that was useful in distinguishing the 72 cultivars with parental exclusion index of $99.99 \%$. These primers can be used in further research with the cultivars analyzed in this study, as well as in their differentiation, which can be an important tool in the useful and fast distinction of genotypes. These results are very important, as markers capable of distinguishing cultivars can be used to register new cultivars. Allele pattern and a base pair estimate for the 25 microsatellite loci revealed in the present study are a first endeavor to use microsatellite markers in situations of cultivar protection for the melon agribusiness in Brazil.

\section{Conflicts of interest}

The authors declare no conflict of interest.

\section{ACKNOWLEDGMENTS}

The authors thank the Brazilian Agricultural Research Corporation (EMBRAPA) for financial support, the University of Brasília (UnB) and Coordination of Improvement of Higher Level Personnel (CAPES) for their support.

\section{REFERENCES}

Aragão FAZ (2010). Divergência genética de acessos e interação genótipo x ambiente de famílias de meloeiro. Doctoral thesis, Universidade Federal Rural do Semi-Árido, Mossoró.

Bassam BJ, Caetano-Anollés G and Gresshoff PM (1991). Fast and sensitive silver staining of DNA in polyacrylamide gels. Anal. Biochem. 196: 80-83. https://doi.org/10.1016/0003-2697(91)90120-I

Botstein D, White RL, Skolnick M and Davis RW (1980). Construction of a genetic linkage map in man using restriction fragment length polymorphisms. Am. J. Hum. Genet. 32: 314-331.

Buso GSC (2005). Marcadores moleculares e análise filogenética. In: Marcadores moleculares, análise filogenética e Utilização de DNA na análise filogenética (Buso GSC, eds.). Embrapa Recursos Genéticos e Biotecnologia, Brasília.

Faleiro FG (2007). Marcadores genético-moleculares aplicados a programas de conservação e uso de recursos genéticos. (1st ed.) Embrapa Cerrados Press, Planaltina.

Genetics and Molecular Research 16 (3): gmr16039739 
Ferreira ME and Grattapaglia D (1998). Introdução ao uso de marcadores moleculares em análise genética. 3rd ed. EMBRAPA-CENARGEN Press, Brasília.

Freitas LB and Bered F (2003). Genética e Evolução Vegetal. 1st ed. UFRGS Press, Rio Grande do Sul.

Gama RNC, Santos CAF, Dias RCS and Souza FF (2013). Molecular characterization of watermelon cultivars using microsatellite markers. Hortic. Bras. 31: 522-527. https://doi.org/10.1590/S0102-05362013000400003

Garcia E, Jamilena M, Alvarez JI, Arnedo T, et al. (1998). Genetic relationships among melon breeding lines revealed by RAPD markers and agronomic traits. Theor. Appl. Genet. 96: 878-885. https://doi.org/10.1007/s001220050815

Guerra-Sanz JM (2002). Citrullus simple sequence repeats markers from sequence databases. Mol. Ecol. Notes 2: 223-225. https://doi.org/10.1046/j.1471-8286.2002.00200.x

Henane I, Slimane RB and Jebari H (2015). SSR-based genetic diversity analysis of Tunisian varieties of melon (Cucumis melo L.) and Fakous (Cucumis melo var. flexuosus). Int. J. Adv. Res. 3: 727-734.

Jarret RL, Merrick LC, Holms T, Evans J, et al. (1997). Simple sequence repeats in watermelon (Citrullus lanatus (Thunb.) Matsum. \& Nakai). Genome 40: 433-441. https://doi.org/10.1139/g97-058

Kaçar YA, Simsek O, Solmaz I, Sari N, et al. (2012). Genetic diversity among melon accessions (Cucumis melo) from Turkey based on SSR markers. Genet. Mol. Res. 11: 4622-4631. https://doi.org/10.4238/2012.November.29.2

Kalinowski ST, Taper ML and Marshall TC (2007). Revising how the computer program CERVUS accommodates genotyping error increases success in paternity assignment. Mol. Ecol. 16: 1099-1106. https://doi.org/10.1111/j.1365294X.2007.03089.X

Kwon YS, Oh YH, Yi SI, Kim HY, et al. (2010). Informative SSR markers for commercial variety discrimination in watermelon (Citrullus lanatus). Genes Genomics 32: 115-122. https://doi.org/10.1007/s13258-008-0674-x

Lynch M (1990). The similarity index and DNA fingerprinting. Mol. Biol. Evol. 7: 478-484.

Mallick MFR and Massui M (1986). Origin, distribution and taxonomy of melos. Sci. Hortic. (Amsterdam) 28: 251-261. https://doi.org/10.1016/0304-4238(86)90007-5

Marshall TC, Slate J, Kruuk LEB and Pemberton JM (1998). Statistical confidence for likelihood-based paternity inference in natural populations. Mol. Ecol. 7: 639-655. https://doi.org/10.1046/j.1365-294x.1998.00374.x

Ohse BJG (2005). Desenvolvimento de marcadores microssatélites (SSRs) para análise genética de melão (Cucumis melo L;). Graduate thesis, Centro Universitário de Brasília, Brasília.

Queiroz MA (2004). Germplasm of curcubitaceae in Brazil. Aust. J. Crop Sci. 4: 377-383.

Ritschel PS, Lins TC, Tristan RL, Buso GS, et al. (2004). Development of microsatellite markers from an enriched genomic library for genetic analysis of melon (Cucumis melo L.). BMC Plant Biol. 4: 9-24. https://doi.org/10.1186/1471$\underline{2229-4-9}$

Rohlf JF (1992). NTSYS-pc Numerical Taxonomy and Multivariate Analysis System, Version 2.2. New York, Exeter Publications.

Shiran B, Amirbakhtiar N, Kiani S, Mohammadi SH, et al. (2007). Molecular characterization and genetic relationship among almond cultivars assessed by RAPD and SSR markers. Sci. Hortic. (Amsterdam) 111: 280-292. https://doi. org/10.1016/j.scienta.2006.10.024

Staub JE, Dnin-Poleg Y, Fazio G, Horejsi T, et al. (2000). Comparative analysis of cultivated melon groups (Cucumis melo L.) using random amplified polymorphic DNA and simple sequence repeat markers. Euphytica 115: 225-241. https:// doi.org/10.1023/A:1004054014174

Tzuri G, Portnoy V, Daube-Mozes M and Katzir N (2006). Genetic diversity of melon (Cucumis melo L.) estimated by SSR markers. Rep. Cucurbit Genet. Coop. 28: 14-16.

\section{Supplementary material}

Table S1. List of Inodorus melons and PIs utilized in this study. Number: Number assigned to the access; Cultivar: cultivar name; Type: Varietal type.

Table S2. List of Cantaloupensis melons utilized in this study. Number: Number assigned to the access; Cultivar: cultivar name; Type: Varietal type.

Table S3. List of selected and utilized primers with their respective sequences (forward and reverse) and annealing temperatures.

Table S4. Descriptive measurements for variability studies based on 44 SSR polymorphic markers in 73 melon cultivars belonging to Inodorus and Cantaloupensis groups, estimated by CERVUS software.

Genetics and Molecular Research 16 (3): gmr16039739 
Figure S1. Dendrogram of the 72 cultivars generated from the 44 SSR primers analyzed. 1 and 2: major groups; 1.1 and 1.2: subgroups of group 1; 2.1 and 2.2: subgroups of group 2.

Figure S2. Dendrogram of the 72 cultivars and 15 PIs generated from the analysis of 44 SSR primers. 1 and 2: major groups; 1.1 and 1.2: subgroups of group $1 ; 2.1$ and 2.2: subgroups of group 2.

Genetics and Molecular Research 16 (3): gmr16039739 